\title{
Literatura chilena de exilio, un vacío epistemológico
}

\author{
Chilean literature of exile, an epistemological emptiness
}

\author{
Sol Marina Garay C. \\ Universidad Autónoma de Madrid, Departamento de Lingüística General, Lenguas Modernas, Lógica y \\ Filosofía de la Ciencia, Teoría de la Literatura y Literatura Comparada. \\ Madrid, España. Correo electrónico: sol.garay@gmail.com / sol.garay@uam.es
}

Este artículo se presenta como una reflexión acerca del desinterés actual que supone, dentro del panorama literario en Chile, el estudio de la literatura creada por autores y autoras chilenas durante el exilio chileno ocurrido entre 1973 y 1989. Una reflexión que espero sirva como referente para aquellos investigadores que se interesen por estudiar y dar a conocer los diversos corpus literarios vinculados al exilio chileno vivido en diferentes países del mundo. Una producción literaria aún por desvelar y que agrupa un conjunto de corpus literarios que nos hablan del pasado reciente de Chile y sus habitantes, una literatura chilena de exilio en la cual las experiencias de dolor y desarraigo dan paso a la apertura al otro y al encuentro con diversas memorias culturales.

Palabras clave: exilio, literatura, memoria, vacío epistemológico.

This paper presents a reflection on the current lack of interest within the literary scene of Chile related to the study of literature created by Chilean authors during their exile abroad between 1973 and 1989. A reflection that I hope will serve as a reference for those researchers who are interested in studying and publicizing the different literary corpus that came up during the Chilean exile in different countries all over the world. A literature which is still to reveal and that groups together a wide range of literary corpus telling the story of the recent past suffered by Chile and its people, a Chilean literature of exile in which the experiences of pain and uprooting paved the way for an opening to each other as well as for the meeting and the interaction of various cultural memories.

Key words: exile, literature, memory, epistemological emptiness.

\section{INTRODUCCIÓN}

Reactualizar el estudio de la literatura creada durante el exilio chileno es una tarea que se inscribe dentro de la necesidad de llenar aquellos vacíos que aún existen respecto a la historia de la literatura chilena contemporánea. Hacer memoria acerca de la producción literaria surgida en el contexto del exilio significa "abrir fisuras en los bloques de sentido que la historia creía haber cerrado como pasados finitos, para quebrar sus verdades unilaterales con los pliegues y dobleces de la interrogación crítica" (Richard 2007: 144). Pues, pese a que los hechos pasados no pueden 
ser cambiados, puesto que ya han ocurrido, el sentido de estos hechos puede ser reinterpretado y resignificado desde la perspectiva del presente y en vista de un futuro no muy lejano. En este sentido, compartimos la opinión de Andrea Pagni acerca de que "no es la concepción de futuro la que da sentido al pasado: por el contrario, es el modo de relacionarnos con el pasado el que le da o le puede dar algún sentido al futuro, justamente en momentos en que ese futuro puede estar perdiendo su sentido" (Pagni 2005: 173-174). Asimismo, es posible observar que el trabajo de la memoria que realizan las primeras obras literarias creadas durante el exilio chileno, así como aquellas que son publicadas con posterioridad, forman parte de lo que la investigadora argentina Elizabeth Jelin (2002) denomina "memorias alternativas". Es decir, aquellas memorias que surgen como respuesta a la brutalidad de los regímenes dictatoriales o autoritarios, las cuales suelen ser transmitidas de manera oral o a través de escritos marginales y cuya repercusión es bastante escasa a nivel nacional.

Durante los períodos dictatoriales de este siglo -(...)- el espacio público está monopolizado por un relato políticamente dominante, donde «buenos» y «malos» están claramente identificados. La censura es explícita, las memorias alternativas son subterráneas, prohibidas y clandestinas, y se agregan a los estragos del terror, el miedo y los huecos traumáticos que generan parálisis y silencio (Jelin 2002: 41-42).

El trabajo de la memoria es fundamental en toda sociedad cuya historia ha estado marcada por complejos acontecimientos de carácter político-social, como dictaduras, totalitarismos o guerras civiles, pues las fracturas provocadas por la violencia ejercida durante periodos autoritarios como la dictadura militar en Chile (1973-1989) no se borran simplemente con el levantamiento de monumentos conmemorativos o con la celebración de homenajes a las víctimas. Esas fracturas requieren de un trabajo continuo y metódico que ayude a sanarlas y a elaborar una memoria donde tengan cabida diversos discursos acerca del pasado y su sentido en el presente/futuro. Al respecto, Elisabeth Jelin comenta lo siguiente:

(...) es imposible encontrar una memoria, una visión y una interpretación únicas del pasado, compartidas por toda una sociedad... pueden encontrarse momentos en que el consenso es mayor, en que un «libreto único» del pasado es más aceptado o aun hegemónico... Sin embargo... Siempre habrá otras historias, otras memorias e interpretaciones alternativas, en la resistencia, en el mundo privado, en las «catacumbas» (Jelin 2002: 5-6).

Por lo tanto, pese a que es imposible unificar un mismo recuerdo para todos aquellos que vivieron tales experiencias, es importante dar cabida en la actualidad a todas aquellas memorias que han pretendido hacer una interpretación crítica del pasado como posibilidad de construir un futuro común. En este sentido, la recuperación de la memoria desde las distintas instancias de la sociedad, oficiales o alternativas, se plantea como una tarea ineludible para evitar volver a repetir aquellas acciones que en el pasado produjeron un grave daño en distintas esferas de lo social. De esta manera, considero absolutamente necesaria la reconstrucción de la memoria de la experiencia literaria del exilio chileno como un aporte a la reconstrucción de la identidad nacional del Chile actual. Pues, como plantea la Dra. Ana Ruiz, la "recuperación de la memoria no encuentra su significación únicamente como mero ejercicio académico..."; la reconstrucción de la memoria "ha de formar parte indispensable 
del debate, subvirtiendo, reelaborando, incorporando o rechazando determinados elementos, para constituirse así en observador y observatorio privilegiado para el estudio de la cultura de nuestra comunidad en sus dimensiones actuales y aquellas que habrá de afrontar" (Ruiz 2002: 387). Al respecto, quisiera destacar la opinión de la investigadora Andrea Pagni, quien subraya la importancia de tener la posibilidad de narrar el pasado, por más traumático y doloroso que haya sido. Pues, la narración, ya sea literaria, musical, cinematográfica o plástica, permite articular un presente donde la memoria sea un elemento constitutivo del futuro.

Importa, entonces, tener o no tener palabras para expresar lo vivido, importa tener o no tener la posibilidad de armar un relato que haga posible la comunicación y la transmisión del recuerdo, para que la experiencia individual se incorpore a la memoria colectiva de una comunidad. Importa tener o no tener derecho de hablar, de ser escuchado y de ser tomado en serio por lo que se dice y acceder a espacios que lo permitan (Pagni 2004: 10).

\section{EstAdo ACTUAL DEL TEMA}

Dentro del ámbito de los estudios literarios chilenos existen algunas publicaciones independientes y, en cierta medida, marginales, que desde finales de los años setenta se han preocupado por analizar el movimiento literario chileno surgido en el exilio. Entre ellas, destaca el artículo "Narrativa chilena después del golpe" (1978) escrito por Antonio Skármeta durante su exilio en Alemania y publicado, por primera vez, en la revista Cambio de México. Posteriormente, apareció el artículo "Poesía chilena en el exilio" (1981) publicado por el hispanista chileno Marcelo Coddou en la revista Hispamérica. Sin embargo, uno de los primeros estudios aparecidos en Chile y dedicados a esta temática fue el libro Literatura chilena en el exilio (1986) de Manuel Alcides Jofré, bajo el respaldo del desaparecido Centro de Indagación y Expresión Cultural Artística (CENECA). Más adelante, en 1990, la académica chilena Soledad Bianchi publicó en la Revista Chilena de Literatura un artículo titulado "Una suma necesaria (Literatura chilena y cambio: 1973-1990)" en el cual lleva a cabo un interesante recorrido a través de las distintas manifestaciones literarias surgidas tanto en el Chile dictatorial como en el exilio. En el contexto de una democracia germinante, uno de los objetivos de este artículo fue abrir un espacio para el diálogo y el análisis de aquella literatura creada, tanto en el interior como en el exterior del país, durante los casi 17 años de dictadura. Posteriormente, Bianchi publicó en Chile el libro Viajes de ida y vuelta. Poetas chilenos en Europa (1993), en el que realizó una destacada recopilación de poemas, la mayoría de ellos inéditos, escritos y/o publicados por poetas chilenos exiliados en diversos países de Europa. En la presentación de esta antología, Bianchi lleva a cabo un breve estudio acerca de la producción literaria del exilio chileno en Europa, haciendo especial hincapié en las características de la producción poética. Junto a estas publicaciones, destacan algunos artículos escritos por el académico de la Universidad Austral de Chile, Iván Carrasco, tales como "Poesía chilena de la última década" (1989), "Tendencias de la poesía chilena en el siglo XX" (1999) y "Literatura intercultural chilena: proyectos actuales” (2005).

Asimismo, cabe destacar la reciente publicación del libro "L" Memoria gráfica del Exilio chileno. 1973 - 1989 (2009) de Estela Aguirre y Sonia Chamorro. Éste, pese a no tratar estrictamente de literatura, lleva a cabo una destacable descripción 
del exilio chileno y los movimientos de solidaridad internacionales vinculados a él, mediante una recopilación de imágenes, fotos y gráficas que nos entregan una interesante mirada acerca de la expresión artístico-cultural surgida durante este período en diversos países del mundo. Anteriormente, Estela Aguirre, Sonia Chamorro y Carmen Correa habían publicado la investigación Bibliografía. Acerca del exilio chileno y la cultura (1993). Juntas, ese mismo año, estas autoras crearon el sitio web chile.exilio.free.fr, un importante referente acerca del exilio chileno y la producción cultural vinculada a esta experiencia.

No obstante, pese a estos antecedentes, aún existe un vacío respecto al estudio de los aspectos filológicos, literarios y lingüísticos que distinguen a las obras de autores chilenos escritas y publicadas en los diversos países del mundo donde ellos encontraron asilo. Un vacío que tiene que ver con un trabajo de análisis e investigación más acabado y más preciso acerca de las características y rasgos que definen a esta producción literaria y que permiten hablar de un movimiento que nace a partir de la experiencia del exilio. Un movimiento literario que surge dentro de una espaciotemporalidad determinada y del cual aún se pueden observar ciertas repercusiones en la literatura chilena actual. Pues, como plantea Iván Carrasco (2006), las consecuencias del golpe militar y las profundas heridas sociales que provocó está situación aún repercuten en la vida de los chilenos y, por tanto, en la creación artística y literaria posterior:

El golpe militar de 1973 y la profunda distorsión de la sociedad, de la historia y de la literatura chilena han constituido un foco de referencia obligado para gran parte de la literatura posterior, signada de una u otra manera por su memoria, sus efectos y su influencia en todos los campos de la vida personal y social (Carrasco 2006: 46).

\section{Vacío epistemológico en los estudios de literatura en Chile}

Durante el período en el cual desarrollé una investigación doctoral (Garay 2011) acerca de la producción literaria del exilio chileno vivido en Alemania entre 1973 y 1989, pude observar el marcado desinterés que evidencian los estudios literarios chilenos actuales por llevar a cabo investigaciones acerca de la literatura producida durante el exilio. Desinterés que produce un importante vacío epistemológico dentro del canon literario nacional y un desconocimiento respecto a la abundante producción de obras literarias escritas y publicadas en el extranjero por autores y autoras chilenos entre los años del exilio. Obras literarias que pueden ser consideradas de gran importancia para la (re)construcción del imaginario cultural y social de la sociedad chilena actual, puesto que trabajan aspectos relevantes de la memoria colectiva nacional, tienden a ser acalladas por los discursos oficiales al ser consideradas como literatura menor o de tipo marginal. Se olvida que se trata de obras literarias que nos entregan una perspectiva innovadora respecto a la relación que establecieron los exiliados con sus respectivas sociedades de acogida, aspecto que influyó decisivamente en el tono de muchas de estas creaciones y que llegó a plantearlas como obras literarias interculturales. Pues, como plantea la profesora de la Universidad Autónoma de Madrid, la Dra. Ana Ruíz: “la literatura constituye... un observatorio privilegiado para el estudio de la cultura de una comunidad y de cómo esta comunidad se apropia de la tradición y la subvierte, la reelabora, y en nuestro 
caso podríamos añadir, incorpora o rechaza nuevos elementos” (Ruiz 2003: 38). En este sentido, considero que la literatura es una lente privilegiada para leer el pasado reciente de Chile, puesto que nos permite observar desde una perspectiva innovadora la evolución de la sociedad chilena, su imaginario cultural y sus perspectivas de futuro, motivos a los cuales siempre aludieron aquellas obras literarias producidas en el exilio.

Entre algunos de los factores que han ayudado a profundizar un vacío dentro del canon literario nacional en lo que se refiere la literatura creada durante el exilio chileno, cabe destacar ciertos antecedentes como el hecho de que en el programa de estudio oficial de la asignatura de "Lengua Castellana y Comunicación" elaborado por el Ministerio de Educación de Chile (MINEDUC) y publicado en el año 2004, el cual es impartido en todos los colegios chilenos durante los últimos cuatro años de enseñanza previos a la finalización del ciclo superior, no se menciona ningún dato acerca de este movimiento literario. Lo más cercano al tema de las literaturas de exilio o migraciones, que aparece en este programa, es la sección en la cual se hace referencia al viaje $e^{1}$ como tema literario, en la cual se propone analizar las diversas formas del viaje dentro la tradición literaria. En esta sección, el programa del MINEDUC sugiere al docente trabajar el tema del exilio, sus consecuencias y sus causas, desde las realidades como la familia, la sociedad y la política de la cultura: "Se puede orientar el sentido del viaje como una situación que dinamiza el acontecer en dichos mundos, afectando la situación de las personas” (Ministerio de Educación del Gobierno de Chiole 2004: 128). Posteriormente, se sugiere la lectura del libro Lejos también el alma se extingue (1932) del autor y dramaturgo húngaro Lajos Zilahy, donde se evoca la nostalgia de tierras y tiempos pasados. Llama la atención que siendo Chile un país que ha vivido una dictadura militar que supuso un masivo éxodo de artistas, intelectuales y escritores que continuaron su trabajo creativo en el exterior, este antecedente no sea mencionado en los programas oficiales de "Lengua Castellana y Comunicación" impartidos en los colegios del país. Más aún, cuando se intenta crear un acercamiento del alumno a la literatura de viaje o exilio se sugiere la lectura de textos completamente ajenos a la realidad chilena, pese a que se dispone de una gran cantidad de obras literarias creadas por escritores chilenos exiliados, en las cuales también se abordan temas como el viaje, el destierro, la nostalgia, la lejanía, el encuentro con la otredad o el contexto político-social. El movimiento literario chileno en el exilio podría, incluso, haber generado todo un capítulo en el cual se hiciera referencia a las expresiones literarias creadas por autores chilenos en el extranjero, donde se analizaran sus características y se estudiaran algunos ejemplos paradigmáticos. Sin embargo, este capítulo no existe dentro del programa de estudios del MINEDUC. Al respecto, considero que algunas de las obras narrativas que podrían ser sugeridas para trabajar el tema del exilio y sus consecuencias dentro del programa de estudios de la asignatura de "Lengua Castellana y Comunicación" son, por ejemplo, la novela Nixpassiert (1978) de Antonio Skármeta, ${ }^{2}$ el libro de relatos Por culpa de nadie (1986) de Carlos Cerda, la antología de cuentos El hombre Golondrina (1997) de Roberto Ampuero, el libro de relatos Erótica de la resistencia (2003) de Omar Saavedra Santis o los libros El pequeño mundo del señor

En este curso ( $3^{\circ}$ medio) los jóvenes tienen entre 16 y 17 años de edad. Este libro fue editado por primera vez en español por la Editorial Pomaire (1980) bajo el título No pasó nada.
Actualmente, existen varias ediciones de este libro publicadas por Ediciones Debolsillo. 
Kaiser y otros cuentos muy breves (2001) y Plan de viajes: cuentos (2005) de Pedro Holz, por nombrar sólo algunos de los más destacados dentro del contexto del exilio chileno vivido en Alemania.

Un fenómeno similar al de la educación secundaria se ha observado dentro de la enseñanza superior, pues, habitualmente, el exilio literario es un tema poco profundizado en los estudios oficiales de literatura y filología hispánica en Chile. Un ejemplo a mencionar es el caso del programa de estudios de la Licenciatura en Letras con mención en Lingüística y Literaturas Hispánicas que imparte la Universidad Católica de Chile. Dentro de este programa de estudios se dicta la asignatura "Narrativa chilena e hispanoamericana", la cual finaliza con el análisis de algunas obras literarias del boom latinoamericano como si se tratara de la última expresión literaria digna de analizar dentro del desarrollo de la literatura hispanoamericana del siglo XX, obviando por completo las diferentes manifestaciones artísticas y literarias surgidas a partir del contexto político autoritario vivido durante las décadas de los sesenta, setenta y ochenta en diversos países de Latinoamérica. Por su parte, la asignatura "Análisis de textos literarios hispanoamericanos", en la cual se pretende dotar al estudiante de herramientas que le permitan elaborar textos literarios, críticos y teóricos, se estudia el tema género y nación en contextos autoritarios desde el estilo neobarroco a través del análisis de obras literarias escritas bajo la dictadura en Chile, en el exilio "interior", por autores como Diamela Eltit y Pedro Lemebel, entre otros. Sin embargo, no se menciona el desarrollo de la literatura chilena creada durante este mismo período fuera de Chile, es decir, en el exilio "exterior". Este antecedente es eliminado del programa de estudio y se da paso al análisis de la literatura creada por autores chilenos durante la década de los noventa bajo el título de La ciudad joven desde el género de las novelas de anti información, donde son estudiadas obras creadas por escritores como Mauricio Electorat, Alberto Fuguet o Roberto Bolaño. Similar es el caso dentro de otros programas de estudio de Licenciatura en Letras o Literatura Hispánica impartidos en diversas universidades chilenas, donde lo habitual es que el tema de la literatura del exilio chileno sea eliminado simplemente del plan académico. En el caso de la Universidad de Chile o la Universidad de Santiago, por ejemplo, si es que se llega a trabajar el tema de la literatura producida durante el exilio chileno, esto se hace dentro de asignaturas electivas que no forman parte del programa obligatorio. Estos antecedentes nos llevan a plantear un evidente vacío ${ }^{3}$ dentro de los contextos escolares y académicos de Chile acerca del estudio y el análisis de la literatura chilena surgida en el extranjero dentro del contexto del exilio que protagonizaron muchos ciudadanos chilenos a partir de 1973.

Estos datos, relativos a la enseñanza secundaria y a la enseñanza superior chilena, son relevantes en la medida en que el colegio y la universidad son agentes educativos, sociales y culturales que ayudan a construir tanto la memoria colectiva como el canon de la literatura de un país. Respecto al concepto de canon literario, comparto la definición planteada por la Dra. Ana Ruiz en su artículo "Desterritorialización y literatura. Literaturas de exilio y migración en la era de la globalización” (2005):

Creo que una excepción puede ser el Magíster en Literatura Hispanoamericana Contemporánea de la Universidad Austral de Chile, donde dicta clases el académico Iván Carrasco. Sin embargo, los estudios de postgrado no son demasiado influyentes dentro de la construcción del canon literario de una nación, puesto que el público para el cual están destinado es muy reducido y su impacto destaca principalmente dentro de las esferas especializadas. 
Entiendo como canon no una entidad abstracta y objetiva suspendida en la atmósfera atemporal del devenir histórico, sino existente sólo en función de una sociedad que lo crea, lo lee y lo interpreta, como hemos indicado al principio, siempre con la intención de comprender y autocomprenderse. (...) Nuestra concepción del canon es por lo tanto siempre la de un canon abierto hacia el futuro, amplio -puesto que siempre admite nuevas inclusiones-, y continuamente revisable (Ruiz 2005: 109-110).

En este sentido, quisiera destacar que la literatura creada por autores chilenos exiliados en diversos países del mundo entre 1973 y 1989 trabajó arduamente por recuperar la memoria y luchar contra el olvido de aquellos acontecimientos que se vivieron bajo la dictadura militar en Chile o durante el exilio. Sucesos complejos y dolorosos, que incluso llegaron a convertirse en un estímulo para la creatividad y para el reconocimiento de la alteridad a través de la literatura. Un primer análisis (Garay 2011) temático respecto a esta producción literaria me ha permitido identificar algunos de los rasgos temáticos y motivos literarios por los que transitan con mayor frecuencia los poemas y narraciones que forman parte de la producción literaria del exilio chileno. Motivos entre los cuales destacan los siguientes: Memoria y recreación del pasado; Escritura testimonial y autobiográfica; Muerte y violencia institucional; Denuncia y reivindicaciones socio-políticas, La nueva dimensión espacio-temporal y el desarraigo; Poética del regreso; Latencia lingüística y reflexión sobre la lengua; Conflictos de pertenencia y encuentro con la alteridad. En el contexto del destierro, la literatura se planteó como un instrumento artístico cuya tarea principal fue reconstruir, narrar y transmitir memorias alternativas que hoy en día podemos trabajar desde una perspectiva crítica y renovadora del pasado. Al respecto, el Dr. Antolín Sánchez Cuervo comenta lo siguiente:

Mediante una singular agudeza epistemológica, la memoria arroja luz sobre ese pasado, relegado a la oscuridad bajo la objetividad historiográfica o absorbido bajo el pasado de los vencedores. Recoge los restos de la cultura que la historia científica tiende a reciclar y desahoga su actualidad crítica, no para reparar anacrónicamente la injusticia significada en ellos, pero sí para impedir, mediante su recuerdo, que el futuro sea una prolongación de la violencia presente (Sánchez Cuervo 2009: 4).

Por lo tanto, el rescate de la memoria colectiva y cultural de la literatura producida durante el exilio chileno se plantea como un aporte a los estudios actuales de literatura en Chile. Pues, mientras la literatura del exilio y su enriquecedora reflexión acerca del ser humano y su relación con la alteridad, la memoria y la interculturalidad no forme parte del debate en torno a los movimientos literarios chilenos del siglo XX, este fenómeno surgido en el destierro será un ausente dentro de la historia de la literatura chilena y, con ello, quedará ausente la capacidad de apertura al otro que provee esta literatura.

Una memoria del exilio a partir de sus propias voces e interlocutores, a menudo ligada a una reflexión sobre la vivencia del exilio y su significación -es decir, a partir de la autorreflexión del propio exiliado- abre en este sentido una perspectiva diferente: el exilio es entonces experiencia subjetiva antes que objeto de un discurso científico, lo cual permite desahogar eso "otro" que ha quedado desprendido de la historia y que sin embargo es clave para reconstruirla críticamente (Sánchez Cuervo 2009: 5). 
Muchos de los chilenos que escribieron obras literarias durante el exilio, escribieron desde la pertenencia a una doble cultura, desde "la presente ajena que se va haciendo propia y la ausente propia que se va haciendo ajena" (Carrasco 1999: 128). Las memorias y referencias socio-culturales relativas al país de origen y el país de acogida, con frecuencia, fueron las fuentes que alimentaron sus respectivos proyectos literarios. Pues, desde el momento en que el escritor deja su tierra originaria para intentar recomenzar su vida en el destierro, no puede abstraerse del impacto que ejerce la sociedad acogida (lengua, cultura, costumbres, tradiciones, horarios, alimentación) en su literatura. En algunos casos, es posible observar que el diálogo entre las distintas memorias que confluyen en el escritor es fluido. Sin embargo, a veces se evidenciará una fuerte confrontación entre ellas e, incluso, sucederá que la alteridad intenta ser eliminada por completo del proyecto literario construido en el exilio. No obstante, a través de los textos que forman parte de esta producción literaria será posible observar que lo otro no sólo se encuentra en el exilio y en la lejanía de la patria, lo otro también es esa patria perdida y difícil de restituir. Solo a partir del reconocimiento en la alteridad se puede recomenzar una historia y, aunque aquí lo que se intenta rescatar es solamente literatura, estos textos pueden decir bastante de aquella historia olvidada que representa el exilio chileno. En definitiva, a través de estos escritos transita disimulada una experiencia de otredad, una experiencia que viene a restituir la presencia del otro en mí, una presencia que no se puede negar.

La mirada de los otros... desnuda aquellas facetas que nosotros mismos no percibíamos; a veces es gracias a este juego de espejos como logramos comprender lo que somos. Y llega un día en que el exiliado termina por habituarse a su condición de desterrado, y mientras se esfuerza en no confesar (se) lo, se da cuenta de aunque la vida lejos del país es dramática, le permite también la pausa indispensable para cualquier reflexión y aprendizaje. El exilio, entonces, se transforma en un verdadero renacimiento (Vásquez \& Araujo 1990:11).

\section{CONCLUSIÓN}

En vista de lo anterior, este artículo se plantea como una invitación a romper con aquel vacío epistemológico que hemos identificado al comienzo, con el fin de demostrar la existencia de un amplio e importante corpus literario vinculado al exilio chileno que merece ser rescatado y analizado dentro de los estudios literarios en Chile. Recobrar la memoria de la literatura creada por autores chilenos exiliados significa recuperar críticamente una escritura que ha querido dar testimonio de un tiempo significativo para la historia de Chile. Significa rescatar una escritura que ha surgido con marcas propias y rasgos característicos. Una escritura que pese a la brutalidad del destierro ha encontrado un espacio para expresarse y que a través del encuentro con una nueva cultura ha logrado enriquecerse. Una literatura que nos invita a descubrir las diversas historias, emociones y vivencias que dan cuenta de un espacio de tiempo que no debe ser olvidado, ya que nos permite reflexionar y extraer valiosos aprendizajes hacia el futuro. Un movimiento literario que debe ser reincorporado dentro de la historia oficial de la literatura chilena, para poder formar parte del canon literario nacional y de la memoria colectiva de este país. En este sentido, vale la pena volver a actualizar este recuerdo, pues reconstruir la memoria de este período nos permitirá analizar críticamente qué es lo que hoy en día nos dan a pensar estas obras literarias 
creadas en el exilio. Hacer memoria de este exilio literario significa volver a darle vida a las voces que deambulan por las novelas, relatos y poemas que forman parte de esta literatura, significa volver a escuchar a las presencias/ausencias que ellas nos evocan.

\section{OBRAs CitADAS}

Aguirre, Estela; Chamorro, Sonia. 2009. "L” Memoria gráfica del Exilio chileno. 1973 1989. Santiago: Ocholibros.

Aguirre, Estela; Chamorro, Sonia; Correa, Carmen. 1993. Bibliografía. Acerca del exilio chileno y la cultura. Santiago: Arcis.

Bianchi, Soledad. 1990. "Una suma necesaria (Literatura chilena y cambio: 1973-1990)". Revista Chilena de Literatura 36: 49-62.

. 1992. Viajes de ida y vuelta: Poetas chilenos en Europa. Santiago de Chile: Documenta.

Carrasco, Iván. 2006. "Ratada de Rosabetty Muñoz: Metáforas de un tiempo cruel”. Revista Chilena de Literatura 69: 45-67.

2005. "Literatura intercultural chilena: proyectos actuales". Revista Chilena de Literatura 66: 63-84.

.1999. "Tendencias de la poesía chilena en el siglo XX". Anales de Literatura Hispanoamericana 28: 157-169.

. 1989. "Poesía chilena de la última década (1977-1987)". Revista Chilena de Literatura 33: 31-46.

Coddou, Marcelo. 1981. "Poesía chilena en el exilio a la luz de ciertos conceptos literarios fundamentales”. Hispamérica 10 (29): 29-39.

Garay C., Sol Marina. 2011. Memoria y exilio a través de la obra de escritores chilenos exiliados en Alemania (1973-1989): una apertura al otro. Tesis Doctoral. Departamento de Lingüística General y Lenguas Modernas, Lógica y Filosofía de la Ciencia, Teoría de la Literatura y Literatura Comparada de la Universidad Autónoma de Madrid.

Jelin, Elizabeth. 2002. Los trabajos de la memoria. Madrid: Siglo XXI Editores.

Jofré, Manuel A. 1986. Literatura chilena en el exilio. Santiago: CENECA.

Ministerio de Educación del Gobierno de Chile (MINEDUC). 2004. Lengua Castellana y Comunicación / Lenguaje y Comunicación/ Programa de Estudio/ Tercero Medio (Segunda edición). Santiago: Ministerio de Educación/ República de Chile.

Muñiz-Huberman, A. 1999. El canto del peregrino. Hacia una poética del exilio. Barcelona: Associació d'Idees-GEXEL/Universidad Autónoma de México.

Pagni, Andrea. 2004. "Memoria y duelo en la narrativa chilena actual: ensayo, periodismo político, novela y cine". En Roland Spiller, T. Heydenreich, W. Hoefler y S. Vergara, Eds. Memoria, duelo y narración. Chile después de Pinochet: literatura, cine y sociedad. Madrid/Frankfurt am Main: Iberoamericana/Vervuert. 9-27.

Richard, Nelly. 2007. Fracturas de la memoria. Arte y pensamiento crítico. Buenos Aires: Siglo XXI.

Riquelme, Horacio. 1993. "Latinoamericanos en Europa. Experiencia de desarraigo y proceso de identidad psicosocial. En Fernando Montupil, Ed. Exilio, Derechos Humanos y Democracia: El exilio chileno en Europa. Santiago, Chile: Servicios Gráficos Caupolicán. Patrocinado por la Coordinación Europea de Comités Pro-Retorno. 145-162.

Ruiz, Ana. 2002. Literatura de emigración de origen español en Alemania (1964-2000): Modelos literarios para una sociedad multicultural. Tesis Doctoral. Departamento de Filología Alemana. Madrid: Universidad Complutense de Madrid. . 2003. "Literatura intercultural frente al canon nacional en Alemania: pautas para la resolución de un conflicto". Revista de Filología Alemana 11: 27-48. 
.2005. "Desterritorialización y literatura. Literaturas de exilio y migración en la era de la globalización”. Exilio y Migraciones 6: 101-112.

Sánchez Cuervo, Antolín. 2009. "Memoria del exilio y exilio de la memoria”. Arbor [Online] 735: 3-11.

Vásquez, Ana; Araujo, Ana María. 1990. La maldición de Ulises. Repercusiones psicológicas del exilio. Santiago: Editorial Sudamericana. 